\title{
REVIEW
}

\section{SARS-CoV-2 and endothelial cell interaction in COVID-19: molecular perspectives}

\author{
Roberta Giordo1, Panagiotis Paliogiannis22, Arduino Aleksander Mangoni ${ }^{3}$ and Gianfranco Pintus $(\mathbb{D} 1,4$ \\ 1Department of Medical Laboratory Sciences, College of Health Sciences, and Sharjah Institute for Medical Research, University of Sharjah, Sharjah, \\ United Arab Emirates \\ 2Department of Medical, Surgical and Experimental Surgery, University of Sassari, Sassari, Italy \\ ${ }^{3}$ Discipline of Clinical Pharmacology, College of Medicine and Public Health, Flinders University and Flinders Medical Centre, Adelaide, Australia \\ ${ }^{4}$ Department of Biomedical Sciences, University of Sassari, Viale San Pietro, Sassari, Italy
}

Correspondence should be addressed to A A Mangoni or G Pintus: arduino.mangoni@flinders.edu.au or gpintus@sharjah.ac.ae

\begin{abstract}
SARS-CoV-2 is the agent responsible for the coronavirus disease (COVID-19), which has been Key Words declared a pandemic by the World Health Organization. The clinical evolution of COVID-19 ranges from asymptomatic infection to death. Older people and patients with underlying medical conditions, particularly diabetes, cardiovascular and chronic respiratory diseases are more susceptible to develop severe forms of COVID-19. Significant endothelial damage has been reported in COVID-19 and growing evidence supports the key pathophysiological role of this alteration in the onset and the progression of the disease. In particular, the - COVID-19

- Sars-CoV-2

- endothelial cell

- endothelial damage

- cardiovascular disease

- ACE2 impaired vascular homeostasis secondary to the structural and functional damage of the endothelium and its main component, the endothelial cells, contributes to the systemic proinflammatory state and the multiorgan involvement observed in COVID-19 patients. This review summarizes the current evidence supporting the proposition that the endothelium is a key target of SARS-CoV-2, with a focus on the molecular mechanisms involved in the interaction between SARS-CoV-2 and endothelial cells.
\end{abstract}

\section{Introduction}

Sars-CoV-2 (severe acute respiratory syndrome coronavirus 2) is the agent responsible for coronavirus disease 2019 (COVID-19), which has been declared a pandemic by the World Health Organization (WHO). According to the WHO report, there were $46,403,652$ cases of COVID19 and 1,198,569 related deaths as of early November 2020 (https://www.who.int/emergencies/diseases/novelcoronavirus-2019). However, the number of cases is likely to be underestimated since a significant proportion of asymptomatic or mildly symptomatic people is not tested for the disease. The infection is transmitted through direct contact with infected persons, via airborne droplets, or indirectly, through contaminated objects or surfaces. The presence of SARS-CoV-2 in fecal swabs and blood suggests additional transmission ways (1). Infected people, both symptomatic and asymptomatic, can transmit the virus (2). SARS-CoV-2 belongs to the family of coronaviridae, with a positive single-strand RNA genome of $\sim 30 \mathrm{~kb}$ nucleotides. Host cell receptor recognition is the first step of the infection. SARS-CoV-2 preferentially interacts with the ACE2 (angiotensin-converting enzyme 2) receptor, although alternative receptors are also available for binding. The virus surface Spike (S) protein, responsible for the coronavirus entry into the cell, contains a receptorbinding domain (RBD) which specifically recognizes ACE2 (3). The cellular proteases transmembrane protease serine 
2 (TMPRSS2) and cathepsin B and L (CatB/L), located on the surface of human cells, then cleave the $S$ protein promoting the fusion of the viral envelope with the host cell membrane. Viral RNA is then released into the cytoplasm and a replication-transcription complex (RTC) is formed, which leads to the generation of additional viral particles $(3,4)$. The clinical evolution of COVID-19 ranges from asymptomatic infection to death. Fever, cough and shortness of breath are the most common symptoms, highlighting the primary involvement of the respiratory system. However, severe cases are also characterized by the presence of excessive systemic inflammation and additional cardiovascular, urinary, hematopoietic, gastrointestinal and nervous system compromise (5, 6). Older people and patients with comorbidities, in particular diabetes, cardiovascular disease, and respiratory disease, are more susceptible to develop severe forms of COVID-19 (7). The presence of excessive systemic inflammation suggests the key pathophysiological role of the endothelium in COVID-19 onset and progression. Vascular endothelial cells form a highly effective barrier between the circulation and peripheral tissues and play a key role in the maintenance of vessel tone, hemostasis, immune response, coagulation and production of extracellular matrix (ECM) components. Significant endothelial dysfunction/injury has been reported in COVID-19 $(8,9,10,11)$. In this review, we discuss the molecular mechanisms involved in the interaction between SARS-CoV-2 and endothelial cells (ECs) and the clinical consequences of this interaction.

\section{ECs and the ACE2 receptor}

The angiotensin-converting enzyme 2 (ACE2) is a transmembrane protein with a large catalytic extracellular domain, which functions both as viral receptor and as metallopeptidase on a wide variety of substrates. As metallopeptidase, ACE2 is part of the renin-angiotensin system (RAS) and plays a primary role in cardiovascular homeostasis, controlling blood pressure and promoting vasodilation. ACE2 catalyzes the hydrolysis of the vasoconstrictor Angiotensin II into Angiotensin I, a vasodilator; the opposite reaction is catalyzed by another enzyme, ACE $(12,13)$. An imbalance between the two enzymes activity with an increase of ACE activation can lead to excessive vasoconstriction and cardiovascular disease development (14). ACE2, previously identified as the receptor that interacts with SARS-CoV (the virus responsible for SARS) (15), is also primarily involved in the entry of SARS-CoV-2 into cells (16). Both viruses share a genome similarity of about $80 \%$ (17), however, the receptor-binding domain (RBD) of the Spike SARS-CoV-2 protein differs from that of the SARS-CoV for several amino acids. This might explain the higher binding affinity to the ACE2 receptor, and consequently, the greater pathogenicity of SARS-CoV2, when compared to SARS-CoV $(18,19)$. The SARS-CoV-2 viral entry into the cell is associated with structural modifications of ACE2 which lead to a loss of its cardioprotective activity (18). Immunolocalization studies report the presence of the ACE2 receptor in many organs and tissues. However, the expression is particularly abundant in vascular ECs and, consequently, in highly vascularized organs such as the lung and the kidney (20). In this regard, recent data obtained in engineered human blood vessel organoids derived frm induced pluripotent stem cells confirmed that SARS-CoV-2 can directly infect blood vessel cells. Indeed, SARS-CoV-2-infected blood vessel organoids showed a viral RNA increasing after 3-6 days post-infection indicating an active viral replication (21). Moreover, since viral particles have a size of $~ 80-100 \mathrm{~nm}$ (22), SARS-CoV-2 preferentially enters into vascular ECs prior to migrating to different organs and tissues, unless a structural and/or functional alteration is present in the infected tissues (22).

\section{The ACE2 receptor is also expressed in precursors of ECs}

Endothelial progenitor cells (EPCs) are a population of bone marrow-derived mononuclear cells (23). A small circulating EPCs subpopulation, characterized by the overexpression of CD34, CD133, and VEGFR-2 markers, possess the ability to transdifferentiate into ECs and play a role in neo-angiogenesis and vascular homeostasis (23, $24,25)$. Recent studies have highlighted the important role of the renin-angiotensin system (RAS) in the physiology of vascular progenitor cells as both ACE and ACE2 are expressed in CD34 positive circulating bone marrow-derived hematopoietic stem/progenitor cells (26). ACE2 deficiency in these cells can promote atherosclerosis, inflammation, bone marrow dysfunction and microvascular complications $(27,28)$. The expression of ACE2 in the stem cell compartment suggests that SARSCoV-2 may potentially infect and damage this important source of cells with consequent long-term deleterious effects on organ and tissue regeneration. In this context, recent studies have reported the expression of both ACE2 and TMPRSS2, two proteases involved in viral activation,

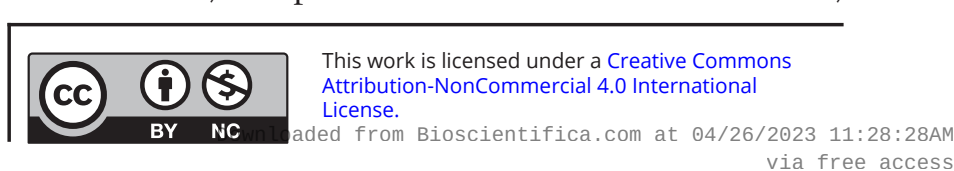


in hematopoietic and ECs precursors known as very small embryonic-like stem cells (VSELs). The ACE2-SARS-CoV-2 interaction in VSELs leads to the activation of NLRP3 inflammasome, a multimeric protein complex responsible for a cascade of inflammatory events that ultimately lead to cell death by pyroptosis (29). Hence, the interaction between Sars-CoV-2 and progenitor cells might negatively impact their regenerative potential, increasing the risk of long-term clinical sequelae.

\section{Alternative receptors for SARS-CoV-2 are highly expressed in ECs}

Although, as discussed, ACE2 represents the main gate entry of SARS-CoV-2 into cells, its expression is reduced in older adults and patients with cardiovascular disease, groups that are particularly susceptible to develop severe infection (30). One possible explanation for this paradox is that ACE2 is not the only entry route for SARSCoV-2. Indeed, alternative receptors that are also highly expressed in ECs, particularly Neuropilin and CD209L, have been proposed as facilitators of viral entry. The CD209L receptor, already known as a target of SARS-CoV infection, is a C-type lectin transmembrane glycoprotein that is highly expressed in human type II alveolar cells and lung ECs (31). CD209L can mediate SARS-CoV-2 entry and infection following recognition and interaction with the RBD domain of the SARS-CoV-2 spike protein. In addition, immunofluorescence analysis of human tissues from SARS-CoV-2 infected organs indicates a high expression of CD209L in the endothelium of small and medium vessels, especially in the lung and the kidney (32). Neuropilin-1 receptor (NRP1) also recognizes and binds to the SARS-CoV-2 spike protein (33). Noteworthy, both NRP1 and protein to neuropilin-2 receptor (NRP2) genes are upregulated in SARS-CoV-2 infected blood vessels (34). NRP1 regulates multiple biological processes, including cardiovascular system development, angiogenesis and formation of neuronal circuits. Analysis of tissues and cells from COVID-19 patients has revealed that the NRP1 receptor is mainly expressed in the epithelium facing the nasal cavity; moreover, NRP1-positive endothelial cells of small and medium-sized vessels have been shown to be infected with SARS-CoV-2. Additional in vivo experiments, using mice infected following intranasal administration of SARS-CoV, have provided evidence that NRP1 can mediate the entry of the virus into the CNS (35). See Fig. 1 for an overview of SARS-CoV-2 activated receptors and tissues/organs involved in COVID-19

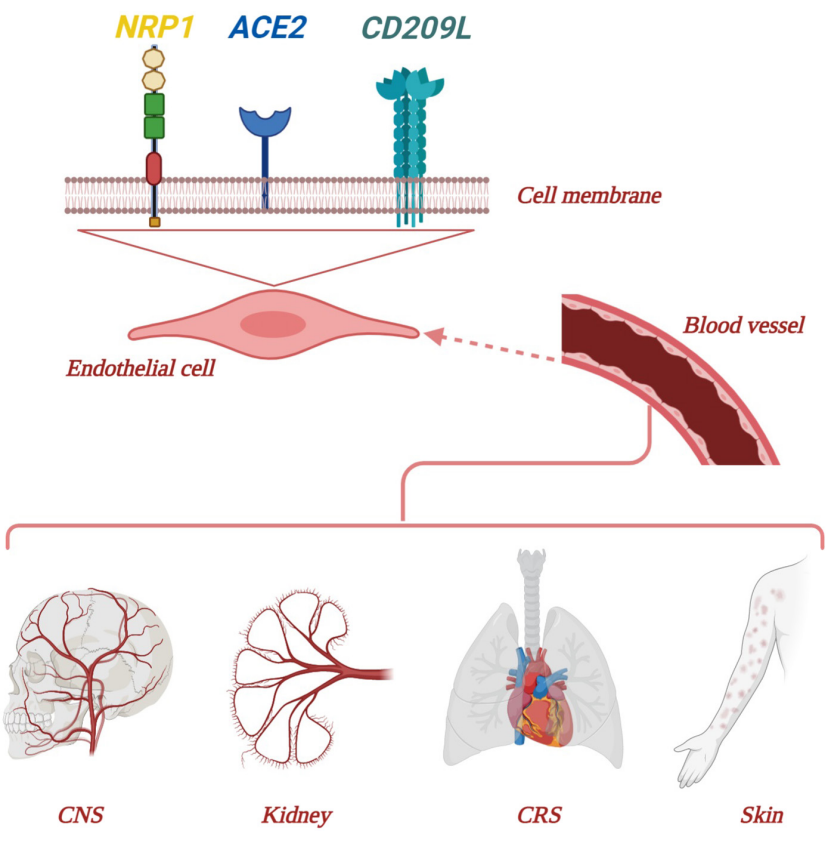

Figure 1

Overview of SARS-CoV-2 entry points into the body and tissues/organs involved in COVID-19. NRP1, Neuropilin-1 receptor; ACE2, angiotensinconverting enzyme receptor; CD209L, C-type lectin transmembrane glycoprotein, also called L-SIGN, DC-SIGNR and DC-SIGN2; CRS, cardiorespiratory system.

\section{SARS-CoV-2 can directly affect ECs and induce endothelial injuries}

The presence of viral particles within ECs of different organs in biopsies of COVID-19 patients is a clear evidence of direct endothelium infection. Viral elements have been found not only in ECs of the most affected organs, such as the lung, heart, and kidney, but also of the skin (34, 36, 37). COVID-19-related cutaneous involvement is heterogeneous for type, onset and symptoms, and secondary to different degrees of inflammation and microvascular damage (38). Chilblain-like skin lesions have raised particular interest among dermatologists since they predominantly affect young people and are mostly asymptomatic or associated with minor COVID19 symptoms. In addition, many of these cases were associated with negative serological and microbiological SARS-CoV-2 tests, making it difficult to establish a causal relationship with COVID-19 (38). However, the presence of SARS-CoV-2 viral particles in ECs from skin biopsies has allowed a direct correlation, indicating chilblain-like lesions as a consequence of COVID-19 (36). A possible explanation for these COVID-19 cutaneous manifestations might be the presence of a non-specific and rapid response of the innate immune system or a

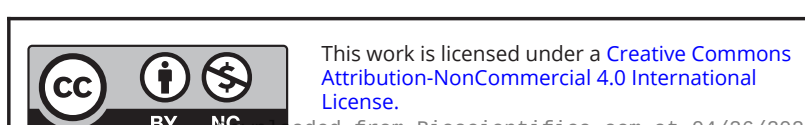
Attribution-NonCommercial 4.0 International 
different antibody response (39). Skin biopsies have also highlighted signs of damage, endotheliitis and thrombosis of small vessel along with EC injury. Endotheliitis, a vascular inflammation characterized by ECs swelling and damage and separation from the underlying basement membrane by subendothelial lymphocytes, is emerging as an important hallmark of SARS-CoV-2 infection. Signs of diffuse endothelial inflammation, accumulation of inflammatory cells, endothelial apoptosis and necrosis have been detected in the lung, heart, kidney, liver, small intestine and skin, as well as the presence of viral elements within ECs $(34,36,37)$. A recent study reported a stroke in a young and previously healthy SARS-CoV-2infected patient without any sign of hyperinflammatory state or blood coagulation activation. However, a significant increase of factor VIII and von Willebrand factor (vWF) indicated endothelial activation. Based on this observation, the authors suggest endotheliitis as a putative cause for the cryptogenic stroke associated with COVID-19 (40). Therefore, widespread endothelial dysfunction and endotheliitis are considered the result of a direct SARS-CoV-2 endothelial invasion which triggers endothelial inflammation with leukocyte recruitment and initiation of innate immune responses. This inflammation status is the cause of micro-thrombotic complications which ultimately lead to deep vein thrombosis, pulmonary embolism and stroke (41). A recent study suggests that the activation of complement pathways is also involved in the development of thrombotic microvascular injuries. Indeed, histological analysis of lungs and skin from COVID-19 patients has showed extensive endothelial and subendothelial deposits of complement components, C4d and C5b-9, within the thrombosed artery. Co-localization of both SARS-CoV-2-specific spike glycoproteins and envelope proteins with $\mathrm{C} 4 \mathrm{~d}$ and C5b-9 was also observed (42). Regardless of the exact triggering event leading to thrombosis, the endothelium is undoubtedly a key pathophysiological target in COVID-19 and its involvement is clinically relevant.

\section{Circulating endothelial cells (CECs) and circulating endothelial progenitors (CEPs) are biomarkers of endothelial damage in COVID-19}

Circulating endothelial cells (CECs) are mature ECs released from the intima into the blood following endothelial damage/stress (43). Increased numbers of CECs have been detected in cardiovascular disease, inflammatory states, infections and ischemia $(43,44)$. CECs are therefore important cellular biomarkers of endothelial health and their increase is directly correlated with disease severity. CECs have been assessed in two studies of 99 and 30 COVID-19 patients, hospitalized or admitted to the intensive care unit (ICU) $(45,46)$. CECs count was significantly higher in patients admitted to ICU and was positively correlated with the length of hospital stay and with an increased concentration of inflammatory cytokines. Therefore, the widespread endothelial injury observed in the severe forms of COVID-19 is a direct consequence of a proinflammatory activation within the vessels (46). A possible limitation of the assessment of CECs in COVID-19 patients is that other concomitant disease states associated with endothelial damage, for example, cardiovascular diseases, diabetes and atherosclerosis, might affect result interpretation. On the other hand, the presence of excessive CECs in COVID-19 patients might reflect increased disease severity and multiorgan involvement (45). To address the issue of distinguishing between viable, necrotic and apoptotic ECs, a study assessed the ratio between viable and apoptotic cells. Although the absolute number of CECs in mild and severe COVID-19 patients was similar to that in healthy controls, the viable/apoptotic CECs ratio indicated that the CECs were less apoptotic in COVID-19 patients that this imbalance was of a greater magnitude than that reported in other vascular diseases or neoplastic conditions $(43,44,47)$. On the other hand, the number of both viable and apoptotic CEPs in COVID-19 patients was higher than healthy controls, however, no correlation with disease severity was observed $(43,44,47)$. An interesting positive correlation was also found between the copies of viral RNA and the percentage of apoptotic CEPs in severe COVID-19 patients which suggests that progenitor cells, as well as mature ECs, might be a direct target of SARS-CoV-2. However, as also suggested by the authors, this hypothesis requires confirmation (48).

\section{Endothelial cell membrane-located human chaperones share epitopes with SARS-CoV-2 and elicit the autoimmune response}

Morphologic and molecular analysis of lungs from patients with SARS-CoV-2 highlight a marked endothelial injury with disruption of intercellular junctions and demolition of the endothelial membrane. This distinctive feature, as well as the presence of SARS-CoV-2 within ECs confirmed also by other studies, suggests that the 
endothelium is the primary site of attack by SARS-CoV (34). As previously discussed, additional features of the SARS-CoV-2 infection include the strong autoimmune and autoinflammatory response and the systemic nature of the disease (49). In this context, molecular chaperones, intracellular molecules expressed under stress conditions, can be released, probably in a modified form, into the extracellular environment as part of the autoimmune response (50). A recent study identifies chaperones that might generate an immunological cross-reactivity due to molecular mimicry phenomena in SARS-CoV-2 infection. Using a bioinformatics prediction tool, the amino acid sequences of all SARS-CoV-2 proteins were compared with 20,365 human proteins. There was an exact identity of six or more amino acids with 17 molecular chaperones. Moreover, the shared peptides were immunogenic epitopes with a high possibility of recognition by the human immune system. Therefore, the molecular chaperones, sharing epitopes with SARS-CoV-2, can potentially elicit a mechanism of autoimmunity where cross-reactive antibodies and effector cells can damage or destroy human cells. Notably, some of the molecular chaperones detected in this study, heat shock proteins HSP90, HSP60 and HSP70 are already known to localize in the EC membrane under stress conditions $(51,52,53)$. This further supports the proposition that the endothelium represents a key target in SARS-CoV-2 infection. Indeed, hypertension and diabetes, main risk factors for COVID19 , are associated with EC stress and consequent release and localization of chaperones on the EC membrane. This condition potentially induces an autoimmune response which in turn exacerbates the SARS-CoV-2 induced endothelial damage (54).

\section{Increased D-dimer in COVID-19 may be related to endothelial cell apoptosis}

There is good evidence that coagulation disorders such as thrombosis, disseminated intravascular coagulation (DIC), and hemorrhage are associated with viral infections (55). Most viral infections can induce DIC, small blood vessel thrombosis due to clot formation. An increasing number of studies have reported that COVID-19 patients with DIC or thrombosis also have abnormal coagulation parameters, particularly high levels of D-dimer and fibrinogen and longer prothrombin times $(56,57)$. ECs produce both anticoagulant (thrombomodulin and antithrombin) and procoagulant (tissue factor and plasminogen activator inhibitor-1) factors and viral infection can trigger EC-mediated coagulation (55). A recent hypothesis suggests that the excess D-dimer in SARS-CoV-2 infection may be the result of a coagulopathy induced by ECs apoptosis (58). Apoptosis is common during viral infection and can result from either a direct interference of the virus with apoptotic pathways or a response of the immune system. In addition, apoptotic vascular ECs exhibit procoagulant activity which contributes to the development of a prothrombotic state (59). EC apoptosis with procoagulant activity has been observed in several viral infections (e.g. human influenza virus, Zika virus, chikungunya) $(58,60,61)$. Endothelial apoptosis in SARS-CoV-2 infection has been demonstrated by Varga et al. by histological analysis of COVID-19 tissues (37). As ACE2 is the main receptor used by SARS-CoV-2 to enter the target cells it is plausible to speculate that tissues or cells carrying the ACE2 receptor are particularly susceptible to virus-induced apoptosis (58).

\section{Endothelial dysfunction is the common denominator of all COVID-19 risk factors}

Although the endothelium has been traditionally considered a simple monolayer of cells that line the interior surface of blood vessels, it has a key role in the regulation of vascular tone and homeostasis. Indeed, beside acting as permeable barrier between the blood and the tissues, it can also respond to physical and chemical signals by releasing a wide range of regulatory factors involved in vascular tone, blood clotting, cellular adhesion and vessel wall inflammation (62). ECsmediated nitric oxide (NO) biosynthesis is instrumental in the maintenance of vascular homeostasis. $\mathrm{NO}$ is responsible for vasodilation, angiogenesis, endothelial cell growth, and protection of vessels from injury. The availability of NO depends on a balance between ROS production and the activity of endothelial nitric oxide synthase (eNOS), responsible for NO synthesis. Indeed, increased oxidative stress is associated with a reduced NO availability and synthesis due to an altered function of eNOS which generates superoxide instead of NO (63). This imbalance between ROS generation and antioxidant defense mechanisms is the primary cause of endothelial dysfunction (64). Endothelial dysfunction can be defined as a systemic pathological state of the endothelium that is characterized by a proinflammatory and procoagulant state. Endothelial dysfunction represents the hallmark of many cardiovascular and metabolic diseases, such as hypertension, chronic heart failure, atherosclerosis, 
diabetes, obesity, as well as chronic inflammatory and autoimmune diseases (65). Dysfunctions of vascular endothelium have also been reported in many viral infections (Influenza A, hemorrhagic viruses, SARS-CoV, Middle East Respiratory Syndrome/MERS-CoV) as well as in SARS-CoV-2 $(66,67,68)$. In fact, viruses can directly (or indirectly by the immune response) damage the vascular endothelium inducing its excessive activation. In this context, the hyperproduction of inflammatory mediators (cytokines storm) and endothelial dysfunction are the hallmarks of COVID-19 patients with a fast and fatal disease progression. Indeed, SARS-CoV infection induces the release of proinflammatory cytokines which, besides to induce the increase of vascular permeability, loss of the normal endothelium antithrombotic and anti-inflammatory functions, are also responsible for the secretion of additional cytokines and chemokines along with platelet activation and leukocyte recruitment $(69,70)$. It is hard to establish whether endothelial dysfunction is the direct outcome of the viral invasion or rather a phenomenon secondary to the virus-elicited cytokine storm. Based on the current knowledge, it is conceivable to assume that both events may occur in parallel. Finally, endothelial dysfunction is the common denominator of both SARS-CoV2 infection and comorbidities (diabetes, obesity, cardiovascular diseases) which are often correlated with the worst outcomes of COVID-19. In the authors' opinion, this also indirectly confirms the important role played by the endothelium in the pathophysiology and clinical evolution of COVID-19. In patients with comorbidities such diabetes, hypertension and cardiovascular disease, as well as older patients, who already exhibit a dysregulation of the redox status, the SARS-CoV2 infection will likely further increase oxidative stress. Indeed, as reported with other viruses, oxidative stress plays an important role also in the pathogenesis of SARS-CoV2 infection. The interplay between oxidative stress and the cytokine storm plays a key role in determining tissue injury, hypoxia, and organ failure (71). Therefore, the detrimental effects of oxidative stress on endothelial function are also biologically and clinically relevant in SARS-CoV2 infection.

\section{Conclusion}

The data summarized in this review indicate the endothelial cell (EC) as a primary SARS-CoV-2 target and support the clinical relevance of endothelial dysfunction in the pathophysiology of COVID-19. ECs are highly present in the major SARS-CoV-2 entry points into the body and the viral infection can directly (or indirectly by the immune response) damage the vascular endothelium, triggering a cascade of events that drives both clot formation and inflammation. Based on the clinical, pathological and molecular features of COVID-19 patients it is plausible to consider COVID-19 as a systemic disease with important hallmarks of vascular damage. Therefore, targeting endothelial cell functions involved in pathways where the endothelium plays a key role, such as hyper inflammation and clotting, might help to attenuate disease progression and/or severity,

\section{Declaration of interest}

Gianfranco Pintus is an Editorial Board Member of Vascular Biology. Gianfranco Pintus was not involved in the review or editorial process for this paper, on which he is listed as an author.

\section{Funding}

This work has been supported by grants from the University of Sharjah, United Arab Emirates (Seed \# 2001050151) to GP, (Collaborative \#2101050160) to GP, AAM, and the University of Sassari, Italy (fondo di Ateneo per la ricerca 2020) to GP.

\section{Author contribution statement}

$R G$ and $G P$ conceived the idea for the article. $R G$ performed the literature review and drafted the manuscript. R G, P P, A A M and G P critically revised the work.

\section{References}

1 Zhang W, Du RH, Li B, Zheng XS, Yang XL, Hu B, Wang YY, Xiao GF, Yan B, Shi ZL, et al. Molecular and serological investigation of 2019nCoV infected patients: implication of multiple shedding routes. Emerging Microbes \& Infections 20209 386-389. (https://doi.org/10.10 80/22221751.2020.1729071)

2 Mishra D, Mishra A, Chaturvedi VK \& Singh MP. An overview of COVID-19 with an emphasis on computational approach for its preventive intervention. 3 Biotech 202010 435. (https://doi. org/10.1007/s13205-020-02425-9)

3 Shang J, Wan Y, Luo C, Ye G, Geng Q, Auerbach A \& Li F. Cell entry mechanisms of SARS-CoV-2. Proceedings of the National Academy of Sciences of the United States of America 2020117 11727-11734. (https://doi.org/10.1073/pnas.2003138117)

4 Mahmoud IS, Jarrar YB, Alshaer W \& Ismail S. SARS-CoV-2 entry in host cells-multiple targets for treatment and prevention. Biochimie 2020175 93-98. (https://doi.org/10.1016/j.biochi.2020.05.012)

5 Jin Y, Yang H, Ji W, Wu W, Chen S, Zhang W \& Duan G. Virology, epidemiology, pathogenesis, and control of COVID-19. Viruses 2020 12 372. (https://doi.org/10.3390/v12040372)

6 Temgoua MN, Endomba FT, Nkeck JR, Kenfack GU, Tochie JN \& Essouma M. Coronavirus disease 2019 (COVID-19) as a multi-

\section{This work is licensed under a Creative Commons Attribution-NonCommercial 4.0 International} License. 
systemic disease and its impact in low-and middle-income countries (LMICs). SN Comprehensive Clinical Medicine 2020 1-11. (https://doi. org/10.1007/s42399-020-00417-7)

7 Yang J, Zheng Y, Gou X, Pu K, Chen Z, Guo Q, Ji R, Wang H, Wang Y $\&$ Zhou Y. Prevalence of comorbidities and its effects in patients infected with SARS-CoV-2: a systematic review and meta-analysis. International Journal of Infectious Diseases 202094 91-95. (https://doi org/10.1016/j.ijid.2020.03.017)

8 Mosleh W, Chen K, Pfau SE \& Vashist A 2020 Endotheliitis and Endothelial Dysfunction in Patients with COVID-19: Its Role in Thrombosis and Adverse Outcomes. Journal of Clinical Medicine 91862. (https://doi.org/10.3390/jcm9061862)

9 Huertas A, Montani D, Savale L, Pichon J, Tu L, Parent F, et al. Endothelial cell dysfunction: a major player in SARS-CoV-2 infection (COVID-19)? European Respiratory Journal 202056 2001634. (https:// doi.org/10.1183/13993003.01634-2020)

10 Sena CM, Pereira AM \& Seiça R. Endothelial dysfunction-a major mediator of diabetic vascular disease. Biochimica et Biophysica Acta 20131832 2216-2231. (https://doi.org/10.1016/j. bbadis.2013.08.006)

11 Widmer RJ \& Lerman A. Endothelial dysfunction and cardiovascular disease. Global Cardiology Science and Practice 20142014 291-308. (https://doi.org/10.5339/gcsp.2014.43)

12 Lambert DW The Cell Biology of the SARS Coronavirus Receptor, Angiotensin-Converting Enzyme 2. Molecular Biology of the SARSCoronavirus, pp. 23-30. Springer, 2010. (https://doi.org/10.1007/9783-642-03683-5_2)

13 Dimitrov DS. The secret life of ACE2 as a receptor for the SARS virus. Cell 2003115 652-653. (https://doi.org/10.1016/s00928674(03)00976-0)

14 Crackower MA, Sarao R, Oudit GY, Yagil C, Kozieradzki I, Scanga SE, Oliveira-dos-Santos AJ, da Costa J, Zhang L, Pei Y, et al. Angiotensinconverting enzyme 2 is an essential regulator of heart function. Nature 2002417 822-828. (https://doi.org/10.1038/nature00786)

15 Li W, Moore MJ, Vasilieva N, Sui J, Wong SK, Berne MA, Somasundaran M, Sullivan JL, Luzuriaga K, Greenough TC, et al. Angiotensin-converting enzyme 2 is a functional receptor for the SARS coronavirus. Nature $2003 \mathbf{4 2 6}$ 450-454. (https://doi. org/10.1038/nature02145)

16 Yang J, Petitjean SJL, Koehler M, Zhang Q, Dumitru AC, Chen W, Derclaye S, Vincent SP, Soumillion P \& Alsteens D. Molecular interaction and inhibition of SARS-CoV-2 binding to the ACE2 receptor. Nature Communications 202011 4541. (https://doi. org/10.1038/s41467-020-18319-6)

17 Zhang RH, Ai X, Liu Y, Li CH \& Zhang HL. Genomic characterization and phylogenetic evolution of the SARS-CoV-2. Acta virologica 2020 64 496-500. (https://doi.org/10.4149/av_2020_403)

18 Gheblawi M, Wang K, Viveiros A, Nguyen Q, Zhong JC, Turner AJ, Raizada MK, Grant MB \& Oudit GY. Angiotensin-converting enzyme 2: SARS-CoV-2 receptor and regulator of the renin-angiotensin system: celebrating the 20th anniversary of the discovery of ACE2. Circulation Research 2020126 1456-1474. (https://doi.org/10.1161/ CIRCRESAHA.120.317015)

19 Tai W, He L, Zhang X, Pu J, Voronin D, Jiang S, Zhou Y \& Du L. Characterization of the receptor-binding domain (RBD) of 2019 novel coronavirus: implication for development of RBD protein as a viral attachment inhibitor and vaccine. Cellular \& Molecular Immunology 202017 613-620. (https://doi.org/10.1038/s41423-0200400-4)

20 Hamming I, Timens W, Bulthuis M, Lely A, Navis G \& van Goor H. Tissue distribution of ACE2 protein, the functional receptor for SARS coronavirus. A first step in understanding SARS pathogenesis. Journal of Pathology 2004203 631-637. (https://doi.org/10.1002/path.1570).

21 Monteil V, Kwon H, Prado P, Hagelkrüys A, Wimmer RA, Stahl M, Leopoldi A, Garreta E, Hurtado Del Pozo C, Prosper F, et al. Inhibition of SARS-CoV-2 infections in engineered human tissues using clinical- grade soluble human ACE2. Cell 2020181 905-913.e7. (https://doi. org/10.1016/j.cell.2020.04.004)

22 Wrapp D, Wang N, Corbett KS, Goldsmith JA, Hsieh CL, Abiona O, Graham BS \& McLellan JS. Cryo-EM structure of the 2019-nCoV spike in the prefusion conformation. Science 2020367 1260-1263. (https://doi.org/10.1126/science.abb2507)

23 Zammaretti P \& Zisch AH. Adult 'endothelial progenitor cells': renewing vasculature. International Journal of Biochemistry \& Cell Biology 200537 493-503. (https://doi.org/10.1016/j. biocel.2004.06.018)

24 Silvestri F, Banavali S, Yin M, Gopal V, Savignano C, Baccarani M \& Preisler HD. CD34-positive cell selection by immunomagnetic beads and chymopapain. Haematologica 199277 307-310.

25 Peichev M, Naiyer AJ, Pereira D, Zhu Z, Lane WJ, Williams M, Oz MC, Hicklin DJ, Witte L, Moore MA, et al. Expression of VEGFR-2 and AC133 by circulating human CD34+ cells identifies a population of functional endothelial precursors. Blood 200095 952-958.

26 Jarajapu YP. Targeting ACE2/angiotensin-(1-7)/mas receptor axis in the vascular progenitor cells for cardiovascular diseases. Molecular Pharmacology 202199 29-38. (htps://doi.org/10.1124/ mol.119.117580)

27 Thatcher SE, Zhang X, Howatt DA, Lu H, Gurley SB, Daugherty A $\&$ Cassis LA. Angiotensin-converting enzyme 2 deficiency in whole body or bone marrow-derived cells increases atherosclerosis in lowdensity lipoprotein receptor-/- mice. Arteriosclerosis, Thrombosis, and Vascular Biology 201131 758-765. (https://doi.org/10.1161/ ATVBAHA.110.221614)

28 Thatcher SE, Gupte M, Hatch N \& Cassis LA. Deficiency of ACE2 in bone-marrow-derived cells increases expression of TNF- $\alpha$ in adipose stromal cells and augments glucose intolerance in obese C57BL/6 mice. International Journal of Hypertension 20122012762094. (https://doi.org/10.1155/2012/762094)

29 Ratajczak MZ, Bujko K, Ciechanowicz A, Sielatycka K, Cymer M, Marlicz W \& Kucia M. SARS-CoV-2 entry receptor ACE2 is expressed on very small CD45- precursors of hematopoietic and endothelial cells and in response to virus spike protein activates the Nlrp3 inflammasome. Stem Cell Reviews and Reports 2020 1-12. (https://doi. org/10.1007/s12015-020-10010-z)

30 Xudong X, Junzhu C, Xingxiang W, Furong Z \& Yanrong L. Age-and gender-related difference of ACE2 expression in rat lung. Life Sciences 200678 2166-2171. (https://doi.org/10.1016/j.lfs.2005.09.038)

31 Jeffers SA, Tusell SM, Gillim-Ross L, Hemmila EM, Achenbach JE Babcock GJ, Thomas WD, Thackray LB, Young MD, Mason RJ, et al. CD209L (L-SIGN) is a receptor for severe acute respiratory syndrome coronavirus. Proceedings of the National Academy of Sciences of the United States of America 2004101 15748-15753. (https://doi. org/10.1073/pnas.0403812101)

32 Amraei R, Napoleon M, Yin W, Berrigan J, Suder E, Zhao G, et al. CD209L/L-SIGN and CD209/DC-SIGN act as receptors for SARS-CoV-2 and are differentially expressed in lung and kidney epithelial and endothelial cells. bioRxiv 2020. (https://doi. org/10.1101/2020.06.22.165803)

33 Daly JL, Simonetti B, Klein K, Chen KE, Williamson MK, AntónPlágaro C, Shoemark DK, Simón-Gracia L, Bauer M, Hollandi R, et al. Neuropilin-1 is a host factor for SARS-CoV-2 infection. Science 2020 370 861-865. (https://doi.org/10.1126/science.abd3072)

34 Ackermann M, Verleden SE, Kuehnel M, Haverich A, Welte T, Laenger F, Vanstapel A, Werlein C, Stark H, Tzankov A, et al. Pulmonary vascular endothelialitis, thrombosis, and angiogenesis in Covid-19. New England Journal of Medicine 2020383 120-128. (https://doi.org/10.1056/NEJMoa2015432)

35 Cantuti-Castelvetri L, Ojha R, Pedro LD, Djannatian M, Franz J, Kuivanen S, et al. Neuropilin-1 facilitates SARS-CoV-2 cell entry and provides a possible pathway into the central nervous system. bioRxiv 2020. (https://doi.org/10.1101/2020.06.07.137802) 
36 Colmenero I, Santonja C, Alonso-Riaño M, Noguera-Morel L, Hernández-Martín A, Andina D, Wiesner T, Rodríguez-Peralto JL, Requena L \& Torrelo A. SARS-CoV-2 endothelial infection causes COVID-19 chilblains: histopathological, immunohistochemical and ultrastructural study of seven paediatric cases. British Journal of Dermatology 2020183 729-737. (https://doi.org/10.1111/bjd.19327)

37 Varga Z, Flammer AJ, Steiger P, Haberecker M, Andermatt R, Zinkernagel AS, Mehra MR, Schuepbach RA, Ruschitzka F \& Moch H. Endothelial cell infection and endotheliitis in COVID19. Lancet 2020395 1417-1418. (https://doi.org/10.1016/S01406736(20)30937-5)

38 Marzano AV, Cassano N, Genovese G, Moltrasio C \& Vena GA. Cutaneous manifestations in patients with COVID-19: a preliminary review of an emerging issue. British Journal of Dermatology 2020183 431-442. (https://doi.org/10.1111/bjd.19264)

39 Santonja C, Heras F, Núñez L \& Requena L. COVID-19 chilblain-like lesion: immunohistochemical demonstration of SARS-CoV-2 spike protein in blood vessel endothelium and sweat gland epithelium in a polymerase chain reaction-negative patient. British Journal of Dermatology 2020183 778-780. (https://doi.org/10.1111/bjd.19338)

40 Crippa S, Kägi G, Graf L, Sauteur PMM \& Kohler P. Stroke in a young adult with mild COVID-19 suggesting endotheliitis. New Microbes and New Infections 202038 100781. (https://doi.org/10.1016/j. nmni.2020.100781)

41 McFadyen JD, Stevens H \& Peter K. The emerging threat of (micro) thrombosis in COVID-19 and its therapeutic implications. Circulation Research 2020127 571-587. (https://doi.org/10.1161/ CIRCRESAHA.120.317447)

42 Magro C, Mulvey JJ, Berlin D, Nuovo G, Salvatore S, Harp J, BaxterStoltzfus A \& Laurence J. Complement associated microvascular injury and thrombosis in the pathogenesis of severe COVID-19 infection: a report of five cases. Translational Research 2020220 1-13. (https://doi.org/10.1016/j.trsl.2020.04.007)

43 Burger D \& Touyz RM. Cellular biomarkers of endothelial health: microparticles, endothelial progenitor cells, and circulating endothelial cells. Journal of the American Society of Hypertension 2012 6 85-99. (https://doi.org/10.1016/j.jash.2011.11.003).

44 Blann AD, Woywodt A, Bertolini F, Bull TM, Buyon JP, Clancy RM, Haubitz M, Hebbel RP, Lip GY, Mancuso P, et al. Circulating endothelial cells. Biomarker of vascular disease. Thrombosis and Haemostasis 200593 228-235. (https://doi.org/10.1160/TH04-090578).

45 Nizzoli ME, Merati G, Tenore A, Picone C, Consensi E, Perotti L, Ferretti VV, Sambo M, Di Sabatino A, Iotti GA, et al. Circulating endothelial cells in COVID-19. American Journal of Hematology 2020 95 E187-E188. (https://doi.org/10.1002/ajh.25881)

46 Guervilly C, Burtey S, Sabatier F, Cauchois R, Lano G, Abdili E, Daviet F, Arnaud L, Brunet P, Hraiech S, et al. Circulating endothelial cells as a marker of endothelial injury in severe COVID-19. Journal of Infectious Diseases 2020222 1789-1793. (https://doi.org/10.1093/ infdis/jiaa528)

47 Mancuso P, Antoniotti P, Quarna J, Calleri A, Rabascio C, Tacchetti C, Braidotti P, Wu HK, Zurita AJ, Saronni L, et al. Validation of a standardized method for enumerating circulating endothelial cells and progenitors: flow cytometry and molecular and ultrastructural analyses. Clinical Cancer Research 200915 267-273. (https://doi. org/10.1158/1078-0432.CCR-08-0432)

48 Mancuso P, Gidaro A, Gregato G, Raveane A, Cremonesi P, Quarna J, Caccia S, Gusso L, Rusconi S, Giacomelli A, et al. Circulating endothelial progenitors are increased in COVID-19 patients and correlate with SARS-CoV-2 RNA in severe cases. Journal of Thrombosis and Haemostasis 202018 2744-2750. (https://doi.org/10.1111/ jth.15044)

49 Galeotti C \& Bayry J. Autoimmune and inflammatory diseases following COVID-19. Nature Reviews. Rheumatology 202016 413-414. (https://doi.org/10.1038/s41584-020-0448-7)
50 Routsias JG \& Tzioufas AG. The role of chaperone proteins in autoimmunity. Annals of the New York Academy of Sciences $2006 \mathbf{1 0 8 8}$ 52-64. (https://doi.org/10.1196/annals.1366.029)

51 Profumo E, Buttari B, Tinaburri L, D'Arcangelo D, Sorice M, Capozzi A, Garofalo T, Facchiano A, Businaro R, Kumar P, et al. Oxidative stress induces HSP90 upregulation on the surface of primary human endothelial cells: role of the antioxidant 7 , 8-dihydroxy-4-methylcoumarin in preventing HSP90 exposure to the immune system. Oxidative Medicine and Cellular Longevity 20182018 2373167. (https://doi.org/10.1155/2018/2373167)

52 Kreutmayer SB, Messner B, Knoflach M, Henderson B, Niederegger $H$, Böck G, Van der Zee R, Wick G \& Bernhard D. Dynamics of heat shock protein 60 in endothelial cells exposed to cigarette smoke extract. Journal of Molecular and Cellular Cardiology 201151 777-780. (https://doi.org/10.1016/j.yjmcc.2011.07.003)

53 Araujo TLS, Venturini G, Moretti AIS, Tanaka LY, Pereira AC \& Laurindo FRM. Cell-surface HSP70 associates with thrombomodulin in endothelial cells. Cell Stress and Chaperones 201924 273-282. (https://doi.org/10.1007/s12192-018-00964-y)

54 Marino Gammazza A, Légaré S, Lo Bosco G, Fucarino A, Angileri F, Conway de Macario E, Macario AJ \& Cappello F. Human molecular chaperones share with SARS-CoV-2 antigenic epitopes potentially capable of eliciting autoimmunity against endothelial cells: possible role of molecular mimicry in COVID-19. Cell Stress and Chaperones 202025 737-741. (https://doi.org/10.1007/s12192-020-01148-3)

55 Goeijenbier M, Van Wissen M, Van De Weg C, Jong E, Gerdes VE, Meijers JC, Brandjes DP \& van Gorp EC. Review: viral infections and mechanisms of thrombosis and bleeding. Journal of Medical Virology 201284 1680-1696. (https://doi.org/10.1002/jmv.23354)

56 Sardu C, Gambardella J, Morelli MB, Wang X, Marfella R \& Santulli G. Hypertension, thrombosis, kidney failure, and diabetes: is COVID-19 an endothelial disease? A comprehensive evaluation of clinical and basic evidence. Journal of Clinical Medicine 202091417. (https://doi.org/10.3390/jcm9051417)

57 Paliogiannis P, Mangoni AA, Dettori P, Nasrallah GK, Pintus G \& Zinellu A. D-dimer concentrations and COVID-19 severity: a systematic review and meta-analysis. Frontiers in Public Health 20208 432. (https://doi.org/10.3389/fpubh.2020.00432)

58 Guler N, Siddiqui F \& Fareed J. Is the reason of increased D-dimer levels in COVID-19 because of ACE-2-induced apoptosis in endothelium? Clinical and Applied Thrombosis/ Hemostasis 2020261076029620935526 . (https://doi. org/10.1177/1076029620935526)

59 Bombeli T, Karsan A, Tait JF \& Harlan JM. Apoptotic vascular endothelial cells become procoagulant. Blood 199789 2429-2442.

60 Sumikoshi M, Hashimoto K, Kawasaki Y, Sakuma H, Suzutani T, Suzuki H \& Hosoya M. Human influenza virus infection and apoptosis induction in human vascular endothelial cells. Journal of Medical Virology $2008 \mathbf{8 0}$ 1072-1078. (https://doi.org/10.1002/ jmv.21185)

61 Anfasa F, Goeijenbier M, Widagdo W, Siegers JY, Mumtaz N, Okba N, van Riel D, Rockx B, Koopmans MPG, Meijers JCM, et al. Zika virus infection induces elevation of tissue factor production and apoptosis on human umbilical vein endothelial cells. Frontiers in Microbiology 201910 817. (https://doi.org/10.3389/fmicb.2019.00817)

62 Deanfield JE, Halcox JP \& Rabelink TJ. Endothelial function and dysfunction: testing and clinical relevance. Circulation 2007115 1285-1295. (https://doi.org/10.1161/ CIRCULATIONAHA.106.652859)

63 Schiffrin EL. Oxidative stress, nitric oxide synthase, and superoxide dismutase: a matter of imbalance underlies endothelial dysfunction in the human coronary circulation. Hypertension $20085131-32$. (https://doi.org/10.1161/HYPERTENSIONAHA.107.103226)

64 Incalza MA, D'Oria R, Natalicchio A, Perrini S, Laviola L \& Giorgino F. Oxidative stress and reactive oxygen species in endothelial dysfunction associated with cardiovascular and

This work is licensed under a Creative Commons Attribution-NonCommercial 4.0 International License. ded from Bioscientifica com at 04/26/2023 11:28:28AM 
metabolic diseases. Vascular Pharmacology 2018100 1-19. (https:// doi.org/10.1016/j.vph.2017.05.005)

65 Davel AP, Wenceslau CF, Akamine EH, Xavier FE, Couto GK, Oliveira HT \& Rossoni LV. Endothelial dysfunction in cardiovascular and endocrine-metabolic diseases: an update. Brazilian Journal of Medical and Biological Research 201144 920-932. (https://doi. org/10.1590/s0100-879x2011007500104)

66 von Smitten K, Eds. Study of tissue injury and repair--a cornerstone of surgical research. Annales chirurgiae et gynaecologiae 199079 63-64.

67 Mackow ER, Gorbunova EE \& Gavrilovskaya IN. Endothelial cell dysfunction in viral hemorrhage and edema. Frontiers in Microbiology 20145 733. (https://doi.org/10.3389/fmicb.2014.00733)

68 Gavriilaki E, Anyfanti P, Gavriilaki M, Lazaridis A, Douma S \& Gkaliagkousi E. Endothelial dysfunction in COVID-19: lessons learned from coronaviruses. Current Hypertension Reports 20202263. (https://doi.org/10.1007/s11906-020-01078-6)

69 Ragab D, Salah Eldin H, Taeimah M, Khattab R \& Salem R. The COVID-19 cytokine storm; what we know so far. Frontiers in Immunology 202011 1446. (https://doi.org/10.3389/ fimmu.2020.01446)

70 Colantuoni A, Martini R, Caprari P, Ballestri M, Capecchi PL, Gnasso A, Lo Presti R, Marcoccia A, Rossi M \& Caimi G. COVID-19 sepsis and microcirculation dysfunction. Frontiers in Physiology 2020 11 747. (https://doi.org/10.3389/fphys.2020.00747)

71 Cecchini R \& Cecchini AL. SARS-CoV-2 infection pathogenesis is related to oxidative stress as a response to aggression. Medical Hypotheses 2020143 110102. (https://doi.org/10.1016/j. mehy.2020.110102)

Received in final form 11 December 2020

Accepted 12 January 2021

Accepted Manuscript published online 13 January 2021 (c) 2021 The authors Published by Bioscientifica Ltd

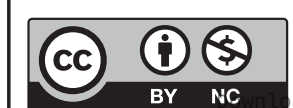

This work is licensed under a Creative Commons Attribution-NonCommercial 4.0 International License.

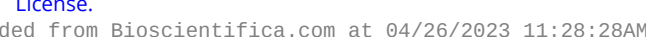

